\title{
O DESENVOLVIMENTO DAS CIÊNCIAS SOCIAIS E A MODERNIZAÇÃO BRASILEIRA
}

\author{
EL DESARROLLO DE LAS CIENCIAS SOCIALES Y LA MODERNIZACIÓN \\ BRASILEÑA
}

THE DEVELOPMENT OF SOCIAL SCIENCES AND BRAZILIAN MODERNIZATION

\author{
Natalia Maria CASAGRANDE ${ }^{1}$ \\ Janaina de OLIVEIRA ${ }^{2}$
}

RESUMO: A intelectualidade vivencia uma ruptura com os padrões de consagração vigentes na Primeira República. A partir da tomada do poder por Getúlio Vargas e a Revolução de 1930, tem-se início um novo cenário político. Devido à queda do preço do café, o modelo agroexportador encontrava-se em processo de decadência, pois já não era mais possível manter artificialmente o valor deste produto. Somam-se a este fator as restrições provocadas pela crise financeira de 1929, o que implicou na queda da demanda externa e no surgimento de novos competidores. Neste contexto, os intelectuais estão subordinados de um modo mais intenso à conjuntura política do que propriamente às questões culturais. A função e atuação dos intelectuais ultrapassam, desta maneira, o campo estritamente intelectual e adentram o do político. Assim, o presente trabalho tem como objetivo demonstrar a relação entre a modernização brasileira e o desenvolvimento institucional e intelectual das Ciências Sociais no Brasil.

PALAVRAS-CHAVE: Modernização. Ciências sociais. Intelectuais. Institucionalização.

RESUMEN: La intelectualidad experimenta una ruptura con los estándares de consagración vigentes en la Primera República. A partir de la toma del poder por Getúlio Vargas y la Revolución de 1930, comenzó un nuevo escenario político. Debido a la caída en el precio del café, el modelo de agroexportación estaba en proceso de descomposición, ya que no era posible mantener artificialmente el valor de este producto. A este factor se suman las restricciones causadas por la crisis financiera de 1929, que implicó una caída de la demanda externa y la aparición de nuevos competidores. En este contexto, los intelectuales están más fuertemente subordinados a la situación política que a los asuntos culturales. La función y el desempeño de los intelectuales, de esta manera, van más allá del campo estrictamente intelectual y entran en el de lo político. Así, el presente trabajo tiene como objetivo demostrar la relación entre la modernización brasileña y el desarrollo institucional e intelectual de las Ciencias Sociales en Brasil.

PALABRAS CLAVE: Modernizacion. Ciencias sociales. Intelectuales Institucionalización.

${ }^{1}$ Universidade Estadual Paulista (UNESP), Marília - SP - Brasil. Doutoranda em Educação. ORCID: https://orcid.org/0000-0002-8939-1540. E-mail: nmcasagrande@gmail.com

${ }^{2}$ Universidade Estadual Paulista (UNESP), Araraquara - SP - Brasil. Doutoranda em Ciências Sociais. ORCID: https://orcid.org/0000-0002-3244-6109. E-mail: janalive@gmail.com 
ABSTRACT: Intellectuality experiences a rupture with the standards of consecration in force in the First Republic. From the seizure of power by Getúlio Vargas and the 1930 Revolution, a new political scenario began. Due to the drop in the price of coffee, the agro-export model was in a process of decay, as it was no longer possible to artificially maintain the value of this product. Added to this factor are the restrictions caused by the financial crisis of 1929, which implied a drop in external demand and the emergence of new competitors. In this context, intellectuals are more intensely subordinated to the political situation than to cultural issues. The function and performance of intellectuals, in this way, go beyond the strictly intellectual field and enter that of the political. Thus, the present work aims to demonstrate the relationship between Brazilian modernization and the institutional and intellectual development of Social Sciences in Brazil.

KEYWORDS: Modernization. Social sciences. Intellectuals. Institutionalization.

\section{Introdução}

Os anos 20 estão inscritos em um contexto de profundas mudanças, que também são simbólicos na história política e cultural brasileira, por inaugurarem a gênese do Brasil Moderno, com a introdução de procedimentos, hábitos, ângulos de visão e diagnósticos que orientaram e mobilizaram várias gerações (LAHUERTA, 1997). Tem-se início um novo cenário político, a partir da tomada do poder por Getúlio Vargas e a Revolução de 1930. O modelo agroexportador encontrava-se em processo de decadência, devido à queda do preço do café, pois já não era mais possível manter artificialmente o valor deste produto. Somam-se a este fator as restrições provocadas pela crise financeira de 1929, o que implicou na queda da demanda externa e no surgimento de novos competidores. Em contrapartida, a industrialização vigora em decorrência da desvalorização da moeda e do encarecimento dos importados.

Neste cenário, o Estado foi fundamental propulsor para a promoção do capitalismo no Brasil, tornando-se primordial para o desenvolvimento nacional, garantindo as condições elementares que impulsionariam e dariam forma ao processo de industrialização. Com o surgimento das estatais, o Estado passou a promover condições para a industrialização, além da figura de principal investidor.

O Governo criou a infraestrutura necessária para o desenvolvimento da industrialização no país, obtendo recursos para a instalação da Companhia Siderúrgica Nacional, a Usina de Volta Redonda; além da construção de estruturas para o transporte marítimo, aéreo e terrestre, o que facilitou o tráfego de insumos e mercadorias. Instituiu também o Conselho Nacional do Petróleo, com o intuito de monopolizar o refinamento e a distribuição do combustível necessário para o desenvolvimento dos transportes. 
A gênese da experiência republicana é um movimento liderado pelos militares, tendo seu impulso inicial distanciado do povo, o qual assistia esse movimento "bestializado", e também ao processo de modernização do Brasil. Desde o princípio, para se institucionalizar, o regime republicano teve a missão de encontrar fórmulas que permitissem a compatibilização entre as novas elites cuja pretensão era instituir o poder público e o poder privado no país, baseado no grande potentado rural, que reinava absolutamente em quase todo o território nacional. Desse modo, a elite rural, através de seu capital, organiza a política nos primeiros anos da República, mas sempre prensando nos seus interesses privados e excluindo a massa deste cenário (LAHUERTA, 1997).

No período da República Velha (1889-1930), São Paulo passou a exercer um papel particularmente relevante, devido à preponderância da economia cafeeira, geradora de um processo acelerado de urbanização, industrialização e modernização econômica. A busca pela hegemonia política empreendida pelas elites paulistas fez da sua capital um centro influente e representou o incremento de sua criação literária, cultural e artística. O mito do bandeirante e a imagem de São Paulo como a locomotiva do país configurariam e legitimariam paulatinamente o domínio paulista.

O projeto de industrialização e de modernização da economia brasileira, conduzido pelo Estado Novo, exigia, além dos investimentos na infraestrutura necessária para o desempenho de uma produção industrial, que se fizesse uma ampla reforma na estrutura administrativa do Estado para ajustá-la aos padrões de desenvolvimento requeridos pela nova conjuntura econômica.

O Estado Novo adotou o chamado Estado de Compromisso, baseado em mecanismos de controle e vias de negociação política responsáveis pelo surgimento de uma ampla frente de apoio ao governo. Isto foi possível por meio de novos órgãos criados pelo Estado, Governo, o Departamento de Imprensa e Propaganda (DIP) que controlava os meios de comunicação e fazia uma propaganda positiva do governo e o Departamento Administrativo do Serviço Público (DASP) que foi o órgão central da reforma administrativa brasileira a partir de 1938, remodelando a estrutura do funcionalismo público, eliminando as práticas nepotistas e outras regalias. Este setor estava encarregado de modernizar a burocracia, instituindo o sistema de mérito, com a introdução dos concursos e de provas de habilitação. Além destas funções, órgãos como DASP, DIP, DEIPs (Departamento Estadual de Imprensa e Propaganda) também acolhiam os intelectuais, mostrando-lhes um caminho seguro para organizar suas produções culturais e, ao mesmo tempo, a fusão da modernidade e projeto nacional (LAHUERTA, 1997). Desse modo, houve uma reestruturação dos padrões administrativos do Estado em decorrência 
do processo de modernização, acionando uma ampla reforma administrativa iniciada com a criação destes órgãos.

Assim, os intelectuais estão subordinados de um modo mais intenso à conjuntura política do que propriamente às questões culturais. A atividade cultural passa a ser, para a elite intelectual, um meio de intervir na política, não dotada de um fim em si mesma. A função e atuação dos intelectuais ultrapassam, desta maneira, o campo estritamente intelectual e adentram o do político. São, portanto, frutos de uma necessidade objetiva, concreta - a de se criar imagens do Brasil que permitam a disseminação da consciência nacional e de se racionalizar a atuação e a formação do Estado nacional, buscando, em última instância, a criação da nação brasileira.

A partir do exposto, o presente trabalho tem como objetivo demonstrar a relação entre a modernização brasileira e o desenvolvimento institucional e intelectual das Ciências Sociais no Brasil, com particularidades que serão expostas no decorrer do texto. Para alcançar tal objetivo, utiliza-se a Revisão bibliográfica como Metodologia, a partir do aporte teórico dos autores trabalhados no decorrer do texto.

\section{Modernização brasileira nos anos 20 e 30}

Para Milton Lahuerta (1997), a conjuntura política e social dos anos 20 instaura uma crise da identidade social, culminando no processo radical de questionamento lançado pela intelectualidade brasileira sobre a própria condição enquanto homens intelectuais, inspirandose nos ideais modernistas difusos. Assim, os anos 30 são permeados pelo desenvolvimento de imagens que se voltam para intelligentsia, através da perspectiva de definir sua identidade social, atribuindo certo caráter missionário e não mercantil.

Neste sentido, a ano de 1922 é um marco simbólico que rompe com o padrão cultural bacharelesco vigente. É neste ano também que acontece a Semana de Arte Moderna, a partir da qual o Modernismo torna-se um ponto de vista na história da cultura nacional. Entretanto, a emergência da ideia de moderno significando ruptura não pode ser plenamente compreendida se deixarmos de considerar que a virada do primeiro pós-guerra foi internacional, abrindo brechas em todos os sistemas culturais com indícios de saturação.

O Modernismo inaugura um novo momento na dialética do universal e do particular, inscrevendo-se com força e até arrogância. A corrente literária estabelecida continua a fluir, mas de um modo menos intenso, ou seja, é sobreposta pelos novos valores. Contudo, retoma certos temas que esta e o Espiritualismo simbolista haviam deixado no ar. Dentre estes, a 
pesquisa lírica tanto no plano dos temas quanto dos meios formais; a indagação sobre o destino do homem e, sobretudo, do homem brasileiro; a busca de uma forte convicção.

A ideia de missão presente nos intelectuais surge desde os primeiros anos da Primeira República, explicando os motivos pelos quais havia a problematização da ordem sob a perspectiva modernista, instalando-se uma força que traz o nacional e o popular para a arena central da intelectualidade. Assim, estes questionamentos estarão presentes na Revolução de 1930 e no Estado Novo, através da implantação de um padrão de produção cultural, mas politizado, como nunca ocorreu na história brasileira. Paralelo, traz-se uma identidade intelectual que se define pela tentativa de construir, como se fossem termos intercambiáveis, a nação, o povo e o moderno, fazendo do Estado o receptor das suas inquietações oriundas dos intelectuais (LAHUERTA, 1997).

Segundo Lahuerta (1997), a tendência de subordinar a dinâmica da sociedade e de seus conflitos ao princípio abstrato da organização vai ser constante nestes anos. Neste contexto, a excitação pedagógica dos anos 30 tem como intuito reformar a sociedade pela educação, através do alargamento de cursos técnico e do desenvolvimento das universidades paulistas para instruir as elites emergentes.

Martins (1987) afirma que o isolamento dos intelectuais criadores também não tem nada de comparável com o vazio social em que vivia a intelligentsia russa. De um modo oposto a esta, no Brasil não havia ao menos um projeto de sociedade, nem a teoria de uma sociedade que seria produzida por um sujeito histórico em formação. Assim, os intelectuais nacionais vão posteriormente atribuir-se, enquanto intelectuais, o papel de demiurgos e de heróis civilizadores da nação - não necessariamente de uma sociedade nova. O sentimento de isolamento que os intelectuais viviam - exprimindo-se antes pela queixa do que pela revolta - relaciona-se também com dois outros fatores:

- $\quad$ País de analfabetos, sem um público e um mercado, no momento em que os valores capitalistas começavam a penetrar fortemente o mundo urbano;

- Campo cultural ainda dominado pela cultura ornamental - havia pouco espaço, seja para o pensamento abstrato, seja para o conhecimento instrumental.

A discussão sobre o alargamento cultural e, ao mesmo tempo, exclusão da massa enquanto privação cultural, pós Revolução de 30, teve grande repercussão na sociedade desta época devido ao papel que as elites desempenhavam neste processo, a partir do seu alto grau de consciência, como detentores da cultura e do saber, com a função de delegados da 
coletividade. Com isso, as elites mantêm posições elevadas, com a consequente sujeição das camadas dominadas e manutenção de seus privilégios e interesses particulares.

\section{Revolução de 1930: Continuidade ou mudança?}

Para Lahuerta (1997), o coroamento da "revolução-passiva de 30" correspondia a uma demanda do Estado, expressando também o processo de unificação cultural, que se traduzia em um projeto sui-generis - a um só tempo modernizador e restaurador dos pilares da nacionalidade. E tudo em nome do bem comum e da construção da nação. De tal forma que um governo forte era implicitamente esperado e, quando concretizado, foi bem aceito por amplos setores. É através da mediação do Estado que se consolida uma cultura política cujo eixo estruturador é um desenvolvimento capitalista excessivamente jurisdicionado e recoberto pela norma do direito que busca sua legitimidade na realização de fins sociais: "[...] o capitalismo avança cumprindo o percurso de uma revolução passiva, na qual a nação não tem identidade própria, é criatura do Estado, sendo organizada como um porto de funcionários a serviço do ideal de expansão da acumulação" (LAHUERTA, 1997, p. 101).

Portanto, se a revolução aprofunda a exigência de renovação, o Estado Corporativo, que se quer Novo, reconhece a necessidade de mudança e de modernização, mas procura domesticar esse impulso transformador. Em nome da ordem e até da tradição, e sempre pleiteando o primado do público sobre o privado, é que o Estado Novo realiza expectativas difusas da sociedade civil, a partir dos ideais dos anos 20. Assim, o movimento de 30 e a sua denominação como revolução, representa apenas pressupostos ideológicos de destruição da memória dos vencidos.

De fato, havia o consenso sobre o caráter de ruptura presente na revolução de 30 , mas também existia a imagem de um marco histórico no processo de constituição tanto do Estado nacional, quanto da própria cultura, gerando um movimento de unificação cultural. Esta relação dicotômica de ruptura/continuidade - revolução e restauração - estão inscritas no movimento de 30. Ou seja, um processo de revolução-passiva, diferentemente de uma revolução popular, explicando a ideia de restauração - possibilidade de transformação de baixo para cima - e da renovação - das novas demandas que são assimiladas e postas em prática pelas velhas camadas dominantes.

No mesmo movimento em que constroem estruturas coercitivas e centralizadas do poder, realizam-se modificações moleculares que incorporam, reconhecendo estas como legítimas e atendendo determinadas demandas da sociedade civil, inclusive as camadas 
subalternas. Este fenômeno - próprio de situações em que o transformismo dá o sentido do desenvolvimento histórico - fica claramente explicitado durante o Estado Novo (DIP), no fim de 1939, visando não só censurar, mas também organizar a produção cultural, imprimindo-lhe um sentido moderno e nacionalista, e da legislação trabalhista, entre outras iniciativas. Após os anos 30, revela a construção do Estado em nome da unificação da nação (LAHUERTA, 1997, p. 101).

Desse modo, o projeto de modernização dos anos 30 não resulta do dinamismo e do empreendimento da sociedade civil, mas sim do Estado, o qual possuía o projeto da modernidade associada ao ideal de construção da nação. Isto através da perspectiva de realizar uma obra de civilização e construção da nação, as quais se colocavam como obras estatais e, ao mesmo tempo, questionando tudo aquilo que não estava inserido neste restrito conceito de civilização e limitada ideia de nação.

Neste sentido, o Estado Novo possuía um caráter repressivo e, simultaneamente, oferecia aos intelectuais perspectivas que satisfaziam suas exigências, procurando dar sentido à sua atividade e engajando-os na construção de um Estado ético e modernizador. Em suma, havia a perspectiva de criar a cultura nacional, fazendo do Estado o instrumento para isso, atribuindo uma "missão" ao intelectual - filosofia que oferecia aos aderentes uma dignidade intelectual, que se desdobrava em um princípio educativo e pedagógico original. Além disso, a atividade escolar, em todos os níveis, tinha extrema importância, inclusive econômica, para os intelectuais. São notórias nesses anos a escassez de possibilidades de ascensão social abertas à iniciativa dos pequenos empreendedores; a inexistência efetiva de partidos; a restrita industrialização - as limitações do mercado cultural; o controle sobre a imprensa, dentre outras.

Sendo assim, a partir da discussão acima, compreende-se que a ampliação do aparato estatal influi na área educacional, proporcionando um espaço privilegiado para a formação de consenso e para o desenvolvimento de um projeto "estadonovista".

\section{Ciências Sociais e o processo de modernização brasileira}

Entre 1930 e 1964, o desenvolvimento institucional e intelectual das Ciências Sociais no Brasil esteve estreitamente associado, de um lado, ao impulso alcançado pela organização universitária e, de outro, à concessão de recursos governamentais para a criação de centros de debate e investigação.

A pesquisa e a produção acadêmica em Ciências Sociais estiveram relacionadas ao desempenho de encargos docentes em meio a uma política mais ampla de profissionalização 
que se refletiu nos professores secundários. Neste contexto, qualquer iniciativa institucional relacionada ao campo das Ciências Sociais esteve atrelada ao sistema político ou aos grupos empresariais que atuavam nos mercados do ensino e da produção cultural.

Há uma completa dissociação entre os cientistas sociais e os interesses dos setores populares. A este respeito, Micelli ressalta que:

As consequiências disso repercutiram tanto sobre as orientações doutrinárias (metodológicas, teóricas, político-partidárias), o perfil dos objetos selecionados para investigação, os conteúdos substantivos da produção acadêmica, como no que concerne às carreiras intelectuais e profissionais dos cientistas sociais, embora alguns desses pioneiros possam resistir e até mesmo recusar ou minimizar essas determinações através de representações imaginárias acerca do relacionamento que acreditam manter com as classes populares (MICELLI, 1987).

Assim, a importância desta discussão se dá à medida que traz à tona o problema das relações entre os cientistas sociais e a sociedade brasileira através de uma qualificação do lugar dos novos "especialistas" da camada intelectual no interior desta formação social. Em meados dos anos 30, manifestam-se os primeiros indícios de uma articulação de interesses entre as novas categorias de produtores intelectuais - os cientistas sociais - por meio da abertura de sociedades científicas, revistas acadêmicas e mandatos de representação em colegiados dentro e fora da universidade (MICELLI, 1987).

Formação de docentes para o ensino secundário - assim os responsáveis pelos cursos de Ciências Sociais consolidavam sua continuidade institucional. Este era um campo profissional seguro, procurado, inclusive, por uma expressiva parcela de acadêmicos de direito cujo intuito era a complementação de renda ou o financiamento dos próprios estudos.

Há, no entanto, uma diferenciação com relação à prática das Ciências Sociais em São Paulo - os cientistas sociais se tornam cada vez mais profissionais acadêmicos; e no Rio de Janeiro - são, em sua maioria, membros por inteiro das elites políticas e culturais. Sobre esta diferença entre Rio de Janeiro e São Paulo, ressalta-se que:

[...] estão na raiz de definições diferentes do sentido da ciência social, prevalecendo no Rio de Janeiro uma concepção "intervencionista", "militante" e "aplicada", cuja expressão intelectualmente acabada são as teorias desenvolvimentistas, enquanto em São Paulo parece se impor uma preocupação marcante com o treinamento metodológico, as leituras dos clássicos, o trabalho de campo individual e/ou em equipe e toda uma socialização acadêmico-disciplinar sob hegemonia do paradigma sociológico funcionalista (MICELLI, 1987, s/p). 
Já em outros Estados como Pernambuco, Bahia e Minas Gerais, o suprimento de praticantes das Ciências Sociais sucedeu através das escolas superiores tradicionais, ou então, por intermédio do trabalho de divulgação exercido por autodidatas. Nestes estados, foram as instituições já estabelecidas do ensino superior que buscaram incorporar as novas disciplinas em suas agendas de preocupações e em seu programa de trabalho, tendo início através do espaço concedido nos órgãos da imprensa local e pela oferta de posições docentes nas escolas normais e secundárias oficiais.

São Paulo, no entanto, foi praticamente o único espaço institucional em que se constitui algo próximo ao que poderia ser qualificado como uma elite de fato intelectual. Em uma perspectiva de história intelectual comparada, a elite de cientistas uspianos é o que mais marca presença. Ressalta-se que as primeiras consequências sobre a vida intelectual brasileira surgida com a criação da Escola de Sociologia e Política e da Faculdade de Filosofia de São Paulo são sentidas somente após vinte anos. Entre 1953 e 1964, os principais integrantes da Escola Paulista produzem suas teses e começam a publicar seus primeiros artigos e livros.

\section{Os desdobramentos dos estudos sociológicos em âmbito societário}

A situação econômica e sociocultural do país repercute em vários pontos que produzem efeitos negativos nas instituições em que o ensino ou a pesquisa no campo da Sociologia podem ser desenvolvidos segundo padrões científicos. Os recursos financeiros disponíveis são insuficientes para fomentar a organização do trabalho científico em bases apropriadas. Caso os recursos financeiros não sejam suficientes, e não haja apoio em uma organização institucional eficiente de investigação sociológica, os sociólogos brasileiros são forçados a limitar-se a projetos de pesquisa que exigem menos dinheiro e que podem receber ajuda de outros investigadores.

As experiências do Brasil nessa área eram então recentes e singelas, fazendo com que as verdadeiras vocações científicas raramente pudessem ser estimadas como produto de uma preparação regular e bem conduzidas. A situação do trabalho dos sociólogos é agravada pelo fato da pesquisa sociológica ser insuficiente em padrões bem definidos de organização interna. Os sociólogos brasileiros devem associar suas ambições teóricas à investigação de fenômenos sociais que acontecem na sociedade comum ao Brasil. Mas não devem esquecer, entretanto, que ao realizarem seus trabalhos, necessitam gerar contribuição tanto para o conhecimento sociológico brasileiro, como para o progresso da Sociologia enquanto ciência. 
Com relação à reação da sociedade no que se refere aos estudos sociológicos, pode-se dizer que o desenvolvimento das investigações científicas está relacionado de maneira árdua à maneira pela qual os leigos representam a importância do saber científico.

\begin{abstract}
Em última análise, as decisões que afetam a posição da ciência na educação, na vida prática e na política de uma nação são tomadas por leigos. Algumas vezes, eles são assistidos por técnicos e especialistas; outras, contam com a capacidade adquirida mediante formação universitária. É claro, porém, que o ideal seria uma situação diferente, que garantisse aos cientistas a oportunidade de se encarregarem dessas decisões ou de exercerem maior influência nas circunstâncias em que elas estão estabelecidas (FERNANDES, 1976, p. 55).
\end{abstract}

Este interesse por parte dos cientistas pela reação societária à ciência e aos seus produtos vem em decorrência do poder da iniciativa dos leigos. Em decorrência deste, os cientistas agem como grupos de pressão, com o intuito de tentar esclarecer a opinião pública através dos meios de propaganda mais acessíveis ou através do apoio de personalidades influentes na administração ou na política. E quando a Sociologia entra neste contexto, o interesse pela reação societária se torna ainda maior, já que a disciplina ainda é desprestigiada.

Além destas questões, convém ressaltar que havia certa defasagem entre o alto nível de formação acadêmica trazido pela missão francesa e pelos professores americanos e as nossas necessidades socioculturais (FERNANDES, 1976). Para Florestan (1976), havia uma espécie de déficit de militância científica entre os seus intelectuais, uma vez que a ciência e a pesquisa deveriam servir ao desenvolvimento nacional autônomo.

Assim, trazendo um panorama das Ciências Sociais no Brasil, Florestan (1976, p.116 apud LAHUERTA, 2005, p. 159) acentua:

Ninguém pode ignorar que é no setor do pensamento científico e tecnológico que o progresso das nações desenvolvidas se mostra mais rápido. Se quisermos atenuar ou superar a distância que nos separa dessas nações, o caminho é um só - conquistar pleno domínio das técnicas sociais modernas, entre as quais se incluem o pensamento científico e a tecnologia fundada na ciência.

\title{
Fernando de Azevedo: Institucionalização das Ciências Sociais e modernização do Brasil.
}

Refletindo acerca da institucionalização da Sociologia no Brasil, Fernando de Azevedo (1962) traz a relação desta e da modernização ocorrida no país entre as décadas de 1930 e 1960. Assim, foi no contexto de modernização institucional do Brasil, desencadeada a partir da década 
de 1930, que se deram as contribuições de Fernando de Azevedo, sobretudo para a institucionalização da Sociologia.

Azevedo (1962) considerou a Sociologia como condição para o progresso da sociedade brasileira ao atribuir-lhe uma função essencial nos diagnósticos e nas soluções dos problemas nacionais. O surgimento das Ciências Sociais “[...] resultou de um esfôrço no sentido de tomar consciência crítica e científica dos problemas que formavam o mosaico brasileiro [...]" (PINTO; CARNEIRO, 1955, p. 15 apud NASCIMENTO, 2010, p. 167). Para estes autores, a partir da Revolução de 1930 tem-se início um ambiente político e social no Brasil que concorreu para criar uma atmosfera de receptividade e expectativa em torno da Sociologia.

No entanto, o consenso sobre a importância do papel da Sociologia na modernização da sociedade e da formação educacional, como instrumento relacionado à intervenção sociológica, não minimizou o dissenso entre a intelectualidade sobre quais deveriam ser os atores sociais responsáveis pelos diagnósticos e soluções dos problemas do Brasil. Após 1930, a fundação e o desenvolvimento de diferentes instituições culturais, de ensino e de pesquisa - influenciadas por intelectuais "católicos" e por "renovadores" - deram início a uma acirrada disputa no mercado de bens simbólicos pelo reconhecimento intelectual, político e estatal, sobre a definição dos agentes condutores e dos projetos privilegiados para a modernização e para a construção da nacionalidade (LAHUERTA, 1997; PÉCAUT, 1990; MICELI, 1979).

Os variados grupos de intelectuais brasileiros compreenderam que as precárias condições educacionais do país, no início do século XX, geravam obstáculos para o crescimento econômico, político e cultural da sociedade. Assim, a difusão do ensino se deu através de uma proposta harmônica para ultrapassar tais barreiras à medida que garantiria a qualificação profissional e a formação humana, com o intuito de assegurar a coesão social e o progresso civilizacional e, simultaneamente, proporcionar ao público letrado o consumo da produção do campo cultural em constituição. Diante deste contexto, a educação tornou-se o instrumento dos variados projetos políticos e intelectuais para intervir na realidade brasileira e propiciar o desenvolvimento do país, estabelecendo as regras de inclusão e de exclusão na cidadania.

A campanha educacional dos anos 20 e 30 constituiu-se através uma intensa mobilização cívica. O conceito "educação", atrelado à condução do mesmo por uma elite, abrangia o trabalho de construção e consolidação de uma hegemonia cultural. Compreendido desta maneira, o discurso cívico da $\mathrm{ABE}^{3}$ produz civismos - civismo do povo laborioso e

\footnotetext{
${ }^{3}$ Associação Brasileira de Educação - ABE - é fundada em 1924, por um grupo de intelectuais que, desiludidos com a República, apostam na educação como solução aos problemas do país.
} 
ordeiro, voltado à produção de riquezas e condução àquilo que é identificado como progresso (CARVALHO, 1997).

Transformar os habitantes em povo - esse era o programa da Associação Brasileira de Educação, que justificava essa iniciativa afirmando que um século após a Independência tínhamos apenas habitantes no Brasil, isto é, indivíduos não moldados para a vivência de um país República. Era, portanto, tarefa das elites organizar e constituir uma nação - elites estas pensadas como o cérebro que dirige um movimento orgânico. $\mathrm{O}$ termo organização traz, dentre outras, a seguinte conotação: "Trata-se de imprimir forma, de produzir estrutura e diferenciação funcional numa sociedade percebida como amorfa, ameboide" (CARVALHO, 1997, p. 124).

A educação que anunciava os intelectuais da Associação deveria ser capaz de transformar cada indivíduo em fator social útil, elevando-o moralmente e fornecendo melhores elementos de felicidade e conforto do que a instrução pura e simples. Isso significava que a educação cívica por eles proposta, inventada através de rituais de formação de corpos saudáveis e de mentes e corações disciplinados, se constituía como um recurso para evitar que a educação, avaliada como arma perigosa, se tornasse um fator de desestabilização social.

Azevedo (1962) foi um importante representante dos pioneiros da educação nova ${ }^{4}$. Este grupo reformador, entre outras bandeiras, destacava a laicidade e a gratuidade da escola pública. O movimento da educação nova no Brasil foi marcado por um conjunto de iniciativas nos âmbitos educacional, cultural e político com o objetivo de revitalizar a educação e a sociedade, por meio de aportes teóricos e metodológicos proporcionados pela Sociologia, Psicologia, Estatística, dentre outras. Como reformador e administrador público Azevedo (1962) desenvolveu um conjunto de iniciativas para criar atores sociais capazes de reestruturar parte do Estado através das suas instituições, com o intuito de dificultar a emergência e a defesa dos interesses privados na esfera pública.

Azevedo (1962) foi procurado por diferentes governos para contribuir na construção da nação por meio do Estado. Assim, é relevante observarmos seus apontamentos sobre a relação entre governo e intelectuais. Para o autor, os governos, sobretudo os ditatoriais, não eram favoráveis aos intelectuais, apoiando-os apenas quando estes não eram considerados como ameaças à estabilidade governamental. Para Azevedo (1962), no entanto, os intelectuais eram capazes de se posicionar contra os interesses políticos ao atuarem nas instituições públicas.

\footnotetext{
${ }^{4} \mathrm{O}$ "Manifesto dos Pioneiros da Educação Nova" consolidava a visão de um segmento da elite intelectual que, embora com diferentes posições ideológicas, vislumbrava a possibilidade de interferir na organização da sociedade brasileira do ponto de vista da educação. Redigido por Fernando de Azevedo, o texto foi assinado por 26 intelectuais, entre os quais Anísio Teixeira, Afrânio Peixoto, Lourenço Filho, Roquette Pinto, Delgado de Carvalho, Hermes Lima e Cecília Meireles.
} 
Na obra "A Cultura Brasileira", Azevedo (1996) articula as contribuições de intelectuais de diversas matrizes políticas e teóricas para a elaboração de uma síntese sobre o tema. Hábil articulador político, Azevedo (1996) realizou importantes empreendimentos organizacionais, entre as décadas de 1920 e 1960, com as contribuições de intelectuais pertencentes a grupos heterogêneos. Azevedo (1996) evitou posturas de embate direto com o governo, por considerar que isto geraria obstáculos aos projetos em que acreditava e, até mesmo, desagregaria os esforços de seus aliados nas lutas institucionais.

Desta forma, Azevedo (1996) posicionou-se como um representante da intelligentsia das Ciências Sociais no Brasil, capaz de liderar inúmeros intelectuais, negligenciar suas diferenças e potencializar aquilo que poderia uni-los. Sobre a trajetória de Fernando de Azevedo enquanto intelectual e homem público, em âmbito nacional, o nome do autor vinculou-se, direta ou indiretamente, às instituições (imprensa, editoras, universidades, institutos de pesquisa) que suscitaram mudanças na mentalidade da sociedade brasileira através de transformações na organização cultural, educacional e política do país, a partir de 1920. Como parte daqueles que contribuíram para o processo de modernização de 1920 a 1960 (e que contou com a colaboração de Azevedo), temos:

[...] jornal $O$ Estado de São Paulo onde realizou dois importantes inquéritos científicos, um sobre educação e outro sobre arquitetura (CAPELATO; PRADO, 1980). O inquérito a respeito da educação forneceu as bases para as propostas de reformas elaboradas e, parcialmente, realizadas por Azevedo seja no Rio de Janeiro (1927), seja em São Paulo (1933) - ao assumir cargos públicos em diferentes conjunturas políticas (governos de Washington Luís e de Getúlio Vargas); bem como para a construção do projeto institucional da USP (NASCIMENTO, 2010, p. 175).

E na esfera editorial, o trabalho de Azevedo (1996) ocorreu no interior da Companhia Editora Nacional - 1931 a 1946. Esta experiência forneceu subsídios para o processo de estruturação do campo editorial brasileiro - ao somar os esforços de Azevedo aos de Octalles Marcondes Ferreira e de Monteiro Lobato para a criação da indústria de livros e do mercado editorial do país. Foi responsável também por tornar Azevedo reconhecido como autor e editor, em diversos países da América e da Europa.

\section{Considerações finais}

Assim, o texto apresentado nos fornece um panorama do desenvolvimento das Ciências Sociais no Brasil, ressaltando o caráter institucional que a disciplina teve no início, porém, sempre atrelado ao caráter intelectual que atualmente conhecemos das Ciências Sociais. 
A formação das Ciências Sociais no Brasil se dá em um cenário marcado por mudanças introduzidas pela modernização. Surge, portanto, a temática da mudança social (LAHUERTA, 2005). Preocupado em atribuir à sua reflexão um caráter sociológico e científico, com o acirramento da conjuntura política, Lahuerta (2005) insere a questão da cidadania como algo a não ser descuidado.

Durante a segunda metade da década de 1950, havia a generalização de que o Brasil possuía contradições não resolvidas e encontrava-se fora do eixo da modernidade, com uma formação europeia que não conseguia completar-se (LAHUERTA, 2005). Neste sentido, a questão que se coloca é a da modernização integral do país, mesmo que as estratégias para atingi-la fossem distintas das efetuadas pelos demais países.

A institucionalização da Sociologia no país se apresenta como uma etapa da história de criação, desenvolvimento e legitimação desta ciência, que apresenta diversas periodizações, sendo uma destas vinculada ao contexto da Revolução de 1930 - quando Fernando de Azevedo ocupou posição singular. Em justificativa à exaltação deste momento histórico, podemos ressaltar que a Revolução de 1930, apesar da representação de uma grande crise econômica e política, foi responsável pelo desencadeamento de um vasto processo de modernização, que fez sentir-se nas décadas seguintes, do qual fez parte uma fase da institucionalização das Ciências Sociais.

Há um estreito relacionamento entre o sistema inclusivo de proteção cultural e o mercado das Ciências Sociais, dentro e fora do circuito universitário. O trabalho intelectual toma forma no espaço universitário em embate com as demandas provenientes dos grandes jornais e revistas ilustradas e de cultura que surgem nesse período. No decorrer das décadas de 30 e 40, os diários editados no eixo Rio de Janeiro / São Paulo concretizavam-se como primordial mercado de divulgação para intelectuais.

E a relevância à temática atribuída à Azevedo (1962) se dá em função dele ter ocupado um lugar destacado tanto para a institucionalização das Ciências Sociais quanto para o processo de modernização do país. Azevedo (1962) definiu a Sociologia como essencial para o progresso da sociedade brasileira, atribuindo-lhe função essencial nos diagnósticos e nas soluções dos problemas nacionais.

Desta forma, a partir do texto apresentado, levanta-se um panorama sobre a institucionalização da Sociologia e a modernização brasileira, percorrendo os trajetos que conferem à disciplina seu caráter atual, bem como o seu papel no processo de modernização brasileira. 


\section{REFERÊNCIAS}

AZEVEDO, F. Máscaras e retratos: estudos literários sobre escritores e poetas do Brasil. São Paulo: Melhoramentos, 1962.

AZEVEDO, F. A cultura brasileira. Brasília: UNB; Rio de Janeiro: UFRJ, 1996.

CARVALHO, M. M. C. de. Educação e política nos anos 20: a desilusão com a República e o entusiasmo pela educação. In: LORENZO, H. C. de; COSTA, W. P. da (Orgs.) A década de 1920 e as origens do Brasil moderno. São Paulo: Editora UNESP, 1997.

FERNANDES, F. A sociologia numa era de revolução social. Rio de Janeiro: Zahar Editores, 1976.

FERNANDES, F. A Sociologia no Brasil. Contribuição para o estudo de sua formação e desenvolvimento. Petrópolis: Vozes, 1977.

LAHUERTA, M. Os intelectuais e os anos 20: moderno, modernista, modernização. In: LORENZO, H. C.; COSTA, W. P. (Orgs.). A década de 1920 e as origens do Brasil moderno. São Paulo: Ed. da Unesp, 1997. p. 93-114.

LAHUERTA, M. Em busca da formação social brasileira: marxismo e vida acadêmica. Perspectivas, São Paulo, v. 28, p. 157-186, 2005.

MARTINS, L. A Gênese de uma intelligentsia: os intelectuais e a política no Brasil, 19201945. Revista Brasileira de Ciências Sociais. v. 2, n. 4, jun. 1987. Disponível em:

http://www.anpocs.org.br/portal/publicacoes/rbcs_00_04/rbcs04_06.htm. Acesso em: 27 fev. 2013.

MICELLI, S. Intelectuais e classe dirigente no Brasil (1920-1945). Rio de Janeiro: Difel, 1979.

MICELLI, S. Condicionantes do desenvolvimento das ciências sociais no Brasil (1930-1964). Revista Brasileira de Ciências Sociais, São Paulo, v. 2, n. 5, 1987.

NASCIMENTO, A. S. Fernando de Azevedo: institucionalização da Sociologia e modernização brasileira. Perspectivas, São Paulo, v. 37, p. 163-190, jan./jun. 2010.

PÉCAUT, D. Os intelectuais e a política no Brasil: entre o povo e a nação. São Paulo: Ática, 1990.

PINTO, L. A. C.; CARNEIRO, E. As ciências sociais no Brasil. Rio de Janeiro: CAPES, 1955. 


\section{Como referenciar este artigo}

CASAGRANDE, Natalia Maria; OLIVEIRA, Janaina de. O desenvolvimento das ciências sociais e a modernização brasileira. Rev. Sem Aspas, Araraquara, v. 8, n. 2, p. 209-224, jul./dez., 2019. e-ISSN: 2358-4238. DOI: https://doi.org/10.29373/sas.v8i2.13358

Submetido em: $11 / 11 / 2019$

Aprovado em: 15/12/2019

Publicado em: 30/12/2019 